\title{
O campo da história e as "obras fronteiriças": \\ algumas observações sobre a produção historiográfica brasileira e uma proposta de conciliação ${ }^{1}$
}

\author{
Raquel Glezer ${ }^{2}$
}

Sara Albieri ${ }^{3}$

\section{Resumo}

Este artigo tem o objetivo de identificar uma situação recente na produção cultural e historiográfica brasileira - o novo surto de "obras fronteiriças" - e propor uma discussão de seu estatuto epistêmico em relação à produção acadêmica. No último quarto de século, a produção acadêmica nacional tem apresentado crescimento constante, decorrente tanto da expansão dos cursos de graduação e de pós-graduação, como do crescimento quantitativo do público leitor de nível educacional mais elevado. Em paralelo, multiplicaram-se o que aqui denominamos de "obras fronteiriças", que contemplam em sua produção elementos da produção acadêmica, mas que em sua construção expositiva utilizam os recursos da narrativa literária com liberdade e liberalidade. A recuperação da discussão sobre fronteiras em teoria da ciência pode ser proveitosa para instruir uma proposta de avaliação historiográfica das "obras fronteiriças".

\section{Palavras-chave}

Teoria da história, historiografia, história e literatura, obras fronteiriças.

1 Este texto é o resultado das comunicações apresentadas em Simpósio Temático realizado no XXIV Simpósio Internacional de História: História e Multidisciplinaridade, organizado pela Associação Nacional de História - ANPUH, em São Leopoldo - RS, em julho de 2007.

2 Professora Titular de Teoria da História do Departamento de História da Faculdade de Filosofia, Letras e Ciências Humanas da Universidade de São Paulo. São Paulo, Brasil. E-mail: raglezer@usp.br

3 Professora Doutora de Teoria da História do Departamento de História da Faculdade de Filosofia, Letras e Ciências Humanas da USP, coordenadora do Programa de Pós-Graduação em História Social do mesmo departamento. São Paulo, Brasil. E-mail: sara@usp.br 


\title{
Historical Fields and "Boundary Works": a commentary on recent Brazilian historiography and a reconciling proposal.
}

\author{
Raquel Glezer
}

Sara Albieri

\section{Abstract}

The goal of this article is to try to identify a rather new configuration in Brazilian cultural and historiographic production - the increase in "boundary works" - and to outline a discussion of their epistemic status as compared to academic historiography. In the last quarter of a century the rising numbers of published academic history books probably reflects the recent expansion of undergraduate and graduate History courses and the increase in more educated readers. This was followed by an equivalent rise in what we here call "boundary works" - historical literature that incorporates academic research procedures but also makes free and liberal use of the resources of literary imagination and narrative. We propose that a return to the discussion of epistemic boundaries in science could be of benefit to an appraisal of the historiographic value of "boundary works".

Keywords:

Theory of history, historiography, history and literature, boundary works 


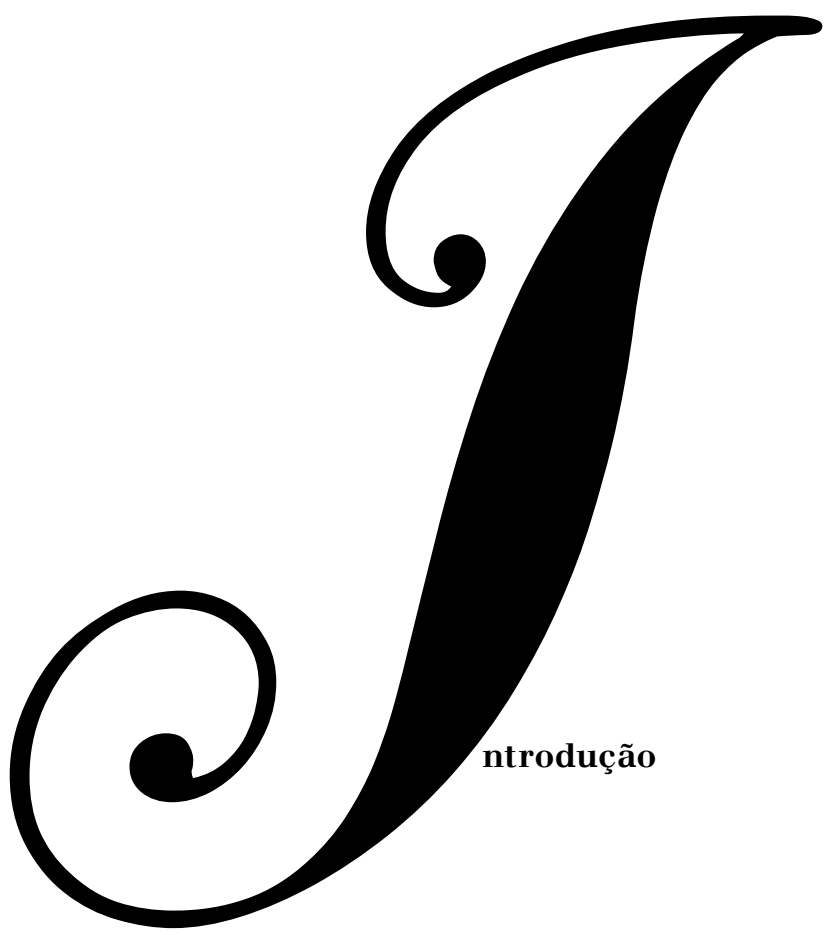

Este texto é o resultado de uma reflexão sobre obras que, para o leitor comum, são consideradas de história, mas para os profissionais do campo situar-se-iam fora da produção historiográfica universitária em senso estrito. Na pesquisa sobre tais produtos culturais encontramos gêneros diversos; destacamos aqui apenas alguns deles. De modo geral, as "obras fronteiriças” podem ser consideradas como uma das formas tradicionais de primeiro contato do leitor com a história, fora do contexto escolar. Enquanto gênero literário, os romances de "capa e espada", por exemplo, encantaram gerações de leitores. Romances históricos como Ivanhoé de Walter Scott $^{4}$, Os Três Mosqueteiros de Alexandre Dumas ${ }^{5}$, Scaramouche de Rafael

4 Walter Scott, considerado o "pai do romance histórico", escritor prolífico, com mais de 70 obras, que marcaram gerações de leitores em muitos países. Suas obras em inglês estão acessíveis na Internet. Ver: <http://www.walterscott.lib.ed.ac. uk/> ; <http://scott.thefreelibrary.com/>; <http://www.online-literature.com/ walter_scott/ $>$; $\quad<$ http://www2.hn.psu.edu/faculty/jmanis/walter-scott.htm>; $<$ http://www.gutenberg.org/etext/82>. Acesso em: 12 jul 2007. A obra mais editada em português, que ainda pode ser encontrada em livrarias é Ivanhoé (1. ed. inglesa 1819). Sobre o tema há um filme de 1952 e uma série de TV de 1982, cf. $<$ http://www.imdb.com/title/tt0044760/>. Foi estudado no Brasil por Maria Odila Dias Curly. O Brasil na historiografia romântica inglesa: um estudo de afinidades de visão histórica: Robert Southey e Walter Scott. Anais do Museu Paulista. São Paulo, tomo XXI, 1967, e por Elisa Lima Abrantes. A Celtificação da Escócia por Walter Scott. 2005. Dissertação (Mestrado em Letras) Universidade Estadual do Rio de Janeiro, 2005.

5 Alexandre Dumas, cujos romances históricos mais conhecidos são Os três mosqueteiros (1. ed. francesa 1844), O conde de Monte-Cristo (1. ed. francesa 1845/ 46), A rainha Margot (1. ed. francesa 1845) e outros. O site com versão integral 
Sabatini $^{6}$, para não citarmos os de Maurice Druon ${ }^{7}$, povoaram com drama e aventura a imaginação especialmente daqueles que, dentre nós, cresceram até os anos 1960. Tais obras competiam entre si pelo gosto do público, embora nem todas tivessem o mesmo apelo. Em nossos dias, mais do que referenciais culturais e geracionais, elas assumiram novos perfis e se transformaram em objetos de estudo, especialmente dos estudos culturais e da história da leitura ${ }^{8}$.

Quanto aos romances históricos nacionais, como as obras de José de Alencar ou de Joaquim Manoel de Macedo, foram deixando de ser percebidos como obras de entretenimento, afastando-se do prazer de ler e do conteúdo histórico romântico, à medida que passaram a portar o estigma da leitura escolar obrigatória, sendo além disso limitados a resumos realizados por outros, com a finalidade de substituir a leitura integral, em tempos de "objetividade do conhecimento".

das obras, bibliografia crítica, histórias em quadrinhos e filmografia, que indica 15 filmes baseados em suas obras, é <http://www.dumaspere.com>. A filmografia internacional, incluindo desenhos animados, séries de TV e DVDs, pode ser localizada em <http://www.allmovie.com/cg/avg.dll?p=avg\&sql=2:309103 T2>. Acesso em: 12 jul. 2007. Suas obras mais conhecidas ainda podem ser encontradas em livrarias. Sobre ele, há alguns estudos no Brasil: CANDIDO, Antonio. Monte Cristo ou da vingança. Rio de Janeiro: Ministério da Educação e Saúde, Serviço de Documentação, 1952; MENDES, Maria Lúcia Dias. Amor e encenação em La reine Margot de Alexandre Dumas. 2002. Dissertação (Mestrado em Literatura Francesa) - Faculdade de Filosofia, Letras e Ciências Humanas, Universidade de São Paulo, 2002;__. A história na visão de Alexandre Dumas. Alea: Estudos Neolatinos, Rio de Janeiro, v. 6, n. 1, jan./jun. 2004 (doi: 10.1590/S1517-106X2004000100006);

No limiar da História e da Memória. Uma leitura de Mes mémoires, de Alexandre Dumas. 2007. Tese (Doutorado em Língua e Literatura Francesa) - Faculdade de Filosofia, Letras e Ciências Humanas, Universidade de São Paulo, 2007; GUIMARÃES, Rosângela Maria Oliveira. Traduções/Adaptações dos Romances-folhetins de Alexandre Dumas no Brasil: estudos de edição e cultura. 2008. Tese (Doutorado em Comunicação e Semiótica) - Pontifícia Universidade Católica de São Paulo, 2008.

6 Rafael Sabatini, escritor anglo-italiano, com obra numerosa, algumas disponíveis em <http://www.gutenberg.org/browse/authors/s\#a640>. Scaramouche foi editada em 1921, tendo sido realizados filmes sobre o livro, cf. <http://www.allocine.fr/ recherche/?rub=0\&motcle=Scaramouche $\& x=65 \& y=14>$. Acesso em: 12 jul. 2007. Existe ainda nas livrarias.

7 Entre os romances históricos de Maurice Druon, destaca-se a série Os reis malditos, sete volumes publicados entre 1955-1977, que deram origem a série de TV francesa, cf. <http://www.allocine.fr/personne/fichepersonne_gen_cpersonne $=38037 . h t m l>$. Suas obras ainda podem ser encontradas nas livrarias.

8 Ver as histórias do livro e da leitura, campo interdisciplinar referencial para os estudos culturais no país. Indicamos, dentre outros, ABREU, Márcia (Org.) Trajetórias do Romance: circulação, leitura e escrita nos séculos XVIII e XIX. Campinas: Mercado de Letras; São Paulo: FAPESP, 2008. 
Outra forma de aproximação lúdica, iniciática, com a história podia ocorrer via coleções de divulgação, tais como a "Tesouro da Juventude" ${ }^{9}$, marco na vida de milhares de jovens leitores, difundida por vendedores em muitas cidades do país, independente de seu tamanho ou da existência de livrarias. Ou mesmo via coleções de obras de história, centradas nas biografias de "grandes homens" e "grandes feitos", como as de Cesare Cantút ${ }^{10}$, H. G. Wells ${ }^{11}$ e Will Durant ${ }^{12}$. As bibliotecas públicas possuíam e possuem exemplares delas, o que é indicativo do papel cultural que desempenharam. A circulação e recepção de tais produtos culturais em nosso país ainda é campo a ser desbravado.

Com o advento dos meios de comunicação de massa, eletrônicos e digitais, poderíamos pensar que deixariam de circular tais obras de divulgação. A queda do interesse pela leitura, mesmo a de entretenimento, tantas vezes alardeada por diversos autores e veículos de comunicação de massa, nos levaria a supor que romances históricos e biografias de personagens de destaque sobreviveriam em bibliotecas como curiosidades ou para estudos eruditos. Se o público comum passou a ler menos, apenas as obras históricas de cunho científico seriam publicadas, destinadas ao reduzido público especializado.

Contudo, o fenômeno que observamos é inverso: o crescimento do mercado editorial em todos os países e mesmo no nosso, com o aumento da quantidade de obras publicadas, em todos os gêneros e, destacadamente nos dois gêneros que escolhemos para análise. Multiplicaram-se as edições de obras de história estrito senso, acompanhando o crescimento do campo científico e da comunidade acadêmica, dispersas entre pequenas, médias e grandes editoras e nas revistas científicas, as quais tiveram extraordinário crescimento nas duas últimas décadas. Mas também cresceram as edições das "obras fronteiriças" que, surpreendentemente, ressurgem para um público com interesse renovado.

9 Esta coleção teve diversas edições, pela W. M. Jackson Editores, dos anos vinte até os anos cinqüenta.

10 CANTÚ, Cesare. História universal. Obra de sucesso com várias edições, entre outras: a) Rio de Janeiro: Fluminense, 1883; b) Rio de Janeiro: Livraria João do Rio, 1931; c) São Paulo: Américas, 1946. 32 v.; d) São Paulo: Edameris, 1970 (ed. resumida).

11 WELLS, H. G. História universal: da ascensão e queda do império romano até o renascimento da civilização ocidental. São Paulo: Nacional, 1939. $3 \mathrm{v}$.

12 DURANT, Will. História da civilização. São Paulo: Ed. Nacional, 1943. 18 v. A obra teve novas edições em 1956 e 1967, e em outras editoras. Continua em circulação e volumes podem ser encontrados em livrarias. Dados sobre sua produção podem ser encontrados na Will Durant Foundation - <http://www.willdurant.com/ home.html>. 
Se o número de livrarias oficialmente ainda é pequeno - só $2.676^{13}$ livrarias estão indicadas e concentradas ainda nos grandes centros urbanos - as bancas de jornal e mostruários em diversos locais atendem aos consumidores de outras formas, para o conhecimento das quais não dispomos de dados precisos ${ }^{14}$. Todavia, a Associação Nacional de Livrarias (ANL) possui um Livrômetro - relógio de leitura no Brasil, indicando os livros lidos no país no ano ${ }^{15}$. E, apesar das reclamações constantes dos empresários do setor, o mercado editorial cresce em volume de publicações e em faturamento, segundo os dados da Câmara Brasileira do Livro ${ }^{16}$. Conforme podemos ver no quadro abaixo, houve crescimento no lançamento de títulos: em 1990, foram 22.479, em 2000, 45.111, e, em 2006, 46.026. Conquanto haja considerável diferença entre os exemplares editados e os vendidos, devemos observar que no mercado editorial, quer no nacional, quer no internacional, a vida útil de um lançamento ou reedição ultrapassa em muito um ano.

1. Quadro com valores da CBL referente à produção e venda

\begin{tabular}{|c|c|c|c|c|}
\hline & \multicolumn{2}{|c|}{$\begin{array}{c}\text { Produção } \\
\left(1^{\mathbf{o}} \text { edição e reedição) }\right.\end{array}$} & Vendas \\
\hline Ano & Títulos & Exemplares & Exemplares & $\begin{array}{c}\text { Faturamento } \\
(\text { R\$) }\end{array}$ \\
\hline 1990 & 22.479 & 239.392 .000 & 212.206 .449 & 901.503 .687 \\
\hline 1991 & 28.450 & 303.492 .000 & 289.957 .634 & 871.640 .216 \\
\hline 1992 & 27.561 & 189.892 .128 & 159.678 .277 & 803.271 .282 \\
\hline 1993 & 33.509 & 222.522 .318 & 277.619 .986 & 930.959 .670 \\
\hline 1994 & 38.253 & 245.986 .312 & 267.004 .691 & 1.261 .373 .858 \\
\hline 1995 & 40.503 & 330.834 .320 & 374.626 .262 & 1.857 .377 .029 \\
\hline 1996 & 43.315 & 376.747 .137 & 389.151 .085 & 1.896 .211 .487 \\
\hline 1997 & 51.460 & 381.870 .374 & 348.152 .034 & 1.845 .467 .967 \\
\hline 1998 & 49.746 & 369.186 .474 & 410.334 .641 & 2.083 .338 .907 \\
\hline 1999 & 43.697 & 295.442 .356 & 289.679 .546 & 1.817 .826 .339 \\
\hline 2000 & 45.111 & 329.519 .650 & 334.235 .160 & 2.060 .386 .759 \\
\hline 2001 & 40.900 & 331.100 .000 & 299.400 .000 & 2.267 .000 .000 \\
\hline 2002 & 39.800 & 338.700 .000 & 320.600 .000 & 2.181 .000 .000 \\
\hline 2003 & 35.590 & 299.400 .000 & 255.830 .000 & 2.363 .580 .000 \\
\hline 2004 & 34.858 & 320.094 .027 & 288.675 .136 & 2.477 .031 .850 \\
\hline 2005 & 41.528 & 306.463 .687 & 270.386 .729 & 2.572 .534 .074 \\
\hline 2006 & 46.026 & 320.636 .824 & 310.374 .033 & 2.880 .450 .427 \\
\hline
\end{tabular}

13 Dados disponíveis no sítio: <http://www.anl.org.br/diagnostico.doc>. Acesso em: 11 nov. 2008.

14 Ver em <http:www.raquelglezer.pro.br/e-edições>, o item Eclética 2005 - História em bancas de jornal.

15 Disponível em <http://www.anl.org.br/>.

16 Cf. <http://www.cbl.org.br/pages.php?recid=58>. Acesso em: 10 nov. 2008. 
Quando vamos ao campo específico de nosso interesse, verificamos que o mercado editorial voltado para a história cresce também no que se refere às obras de divulgação, às biografias romanceadas, às revistas de divulgação histórica - enfim, às obras de "quase história", universo que desconhecemos formalmente. Note-se que, com raras exceções, o mundo universitário especializado não reconhece ou atribui valor às pretensões de produzir conhecimento além de suas fronteiras $^{17}$. Assim, nos anos 1990, ao serem lançados os primeiros volumes das edições que denominamos de "fronteiriças", a comunidade se manifestou de forma contrária a tais produtos, com certo estardalhaço.

\section{As Obras Fronteiriças no Contexto Atual}

Reconhecemos que existem gêneros específicos na produção historiográfica especializada, que podem e devem receber tratamentos analíticos diversos, como são os casos de livros didáticos, manuais universitários e coleções universitárias. Há também as coleções de divulgação de conhecimento histórico - as quais abrangem largo espectro, pois algumas vezes são publicações de trabalhos acadêmicos, e, em outras situações, são apenas reescrita de outros trabalhos. As revistas de divulgação histórica, fenômeno relativamente recente no mercado editorial, devem ser analisadas separadamente, por sua diversidade e complexidade $^{18}$. Existem também as biografias, memórias e obras de divulgação histórica, com ou sem fundamentação em pesquisa documental.

As primeiras obras indicativas do surto atual de "obras fronteiriças" foram as biografias ${ }^{19}$, que para o público leigo estão associadas

17 Ver: AVELINO, Yvone Dias. A grande saga: a viagem cabralina, as primeiras expedições e os primeiros colonizadores. Projeto História. Sentidos da comemoração, São Paulo, v. 20, p. 333, abr. 2000, que resenhou os três primeiros volumes da coleção "Terra Brasilis" de Eduardo Bueno, apontando o tradicionalismo das informações e das interpretações.

18 Vide nota 14.

19 A biografia como gênero erudito historiográfico é uma das formas tradicionais da historiografia literária ou histórica, centrada em pessoas/autores/personagens consideradas indicativas de uma temporalidade, que tiveram alguma atuação destacada. Os catálogos/dicionários/inventários de autores com biografias, mesmo que sumárias, são elementos fundamentais na heurística histórica ou literária, para contato com dados biográficos, bibliografia pré-existente, relação de obras, comentadores etc. Uma discussão atual de biografia pode ser vista em LORIGA, Sabina. A biografia como problema. In: REVEL Jacques (Org.) Jogos de escalas. A experiência da microanálise. Rio de Janeiro, Fundação Getulio Vargas, 1998. p. 225-249. Na historiografia universitária brasileira, tais obras são pouco valorizadas. No recente Dicionário de datas da história do Brasil, organizado por Circe Bittencourt, para a Editora Contexto, em 2007, na introdução, a organizadora sentiu a necessidade de justificar a edição de tal tipo de obra, indicando que as datas 
à história, pois contando fatos das vidas de pessoas notáveis por algum motivo. Escritas em linguagem ficcional, geralmente por jornalistas ${ }^{20}$ - alguns dos quais se tornaram especialistas no gênero - abriram caminho para os historiadores ${ }^{21}$ também se dedicarem a elas, malgrado as tensões que marcam as relações entre Biografia e História ${ }^{22}$. Dois eminentes historiadores lançaram, recentemente, biografias que obtiveram sucesso ${ }^{23}$ - e foram acompanhados por outros ${ }^{24}$. Também há

são suporte da memória e destacando a impossibilidade da existência de atemporalidade na história ou na memória social na perspectiva ocidental. Fatos e fontes são datados, e todas as obras historiográficas são duplamente datadas, contendo em si a do momento em estudo/análise e a do momento da produção.

20 Há autores que se especializaram em biografias, como Fernando Morais, que escreveu Olga, Chatô: o rei do Brasil, Corações Sujos, ou Ruy Castro, com Carmen: uma biografia, e, O Anjo Pornográfico - todas obras relacionadas com momentos marcantes da história do Brasil. Há os autores especializados em biografias de cantores e músicos, como Regina Echevarria, em esportistas e em autores e atores teatrais. O mercado editorial de biografias é tão concorrido que há conflitos judiciais entre autores e assuntos, quer diretamente - como o caso do cantor Roberto Carlos, quer com familiares - como em Garrincha.

21 A editora FGV publicou biografias escritas por historiadores: João Goulart: entre a memória e a história, de Marieta de Moraes Ferreira; Wolff Klabin: a trajetória de um pioneiro, de Carlos Heitor Cony e Sergio T. de N. Lamarão; Henrique Morize e o ideal de ciência pura na República Velha, de Antonio A. Passos Videira; Ernesto Geisel, de Maria Celina Soares D’Araujo e Celso Castro. E na Coleção "Os que fazem a história": João do Rio - A cidade e o poeta - O olhar do flâneur na Belle Époque, de Antonio Edmilson M. Rodrigues; Ezequiel Corrêa dos Santos: um jacobino na corte imperial, de Marcello O. Basile; José Bonifácio: uma historia em três tempos, de Berenice Cavalcante; Nair de Teffé: vidas cruzadas, de Antonio Edmilson M. Rodrigues; Silvio Romero: dilemas e combates no Brasil da virada do séc. XX, de Maria Aparecida R. Mota; Frei Caneca entre Marilia e a pátria, de Marco Morel; e João do Rio: uma biografia, de João Carlos Rodrigues.

22 Essas relações, na perspectiva dos historiadores, foram descritas assim por Teresa Malatian em artigo recente: "A biografia nunca esteve ausente das reflexões historiográficas ou das práticas profissionais dos historiadores, mas muitas vezes se fez acompanhar de um mal-estar explícito ou implícito.” MALATIAN, Teresa Maria. A biografia e a história. Cadernos CEDEM, UNESP, ano 1, no. 1, p. 16-31, jan. 2008. Disponível em: $<$ http://www.cedem.unesp.br/cadernoscedem.pdf>. Acesso em: jun. 2008.

23 MELLO, Evaldo Cabral de. Nassau: governador do Brasil Holandês. São Paulo: Companhia das Letras, 2006; CARVALHO, José Murilo de. D. Pedro II: ser ou não ser. São Paulo: Companhia das Letras, 2007.

24 A Companhia das Letras, que já editava biografias, lançou coleções especializadas: uma delas, com obras de cunho biográfico e/ou autobiográfico, é a "Memória e História", na qual foi editada a obra de LUSTOSA, Isabel. D. Pedro I: um herói sem nenhum caráter. São Paulo: Companhia das Letras, 2006. Outra é a "Perfis Brasileiros", que além das obras citadas na nota 20, relaciona a de Isabel Lustosa, e as de COSTA E SILVA, Alberto. Castro Alves: um poeta sempre jovem. São Paulo: Companhia das Letras, 2006; DORATIOTO, Francisco. General Osório: a espada liberal do Império. São Paulo: Companhia das Letras, 2008; FAUSTO, Boris. Getulio Vargas: o poder e o sorriso. São Paulo: Companhia das Letras, 2006; ALONSO, Ângela. Joaquim Nabuco. 
casos de historiadores que enveredam pelo gênero biográfico romanceado, como o faz Mary del Priore, em O Príncipe Maldito ${ }^{25}$.

Mas, além de historiadores que escrevem biografias de personagens históricas, em narrativa literária, concorrendo com os jornalistas, há outros autores que escrevem obras que classificam de história. Um caso exemplar de hibridismo é o de Jorge Caldeira, jornalista, com Mestrado em Sociologia ${ }^{26}$ e Doutorado em Ciência Política ${ }^{27}$, que publica biografias e obras que define como de história, cruzando especialidades e gêneros literários. Seu primeiro livro foi uma biografia de Mauá ${ }^{28}$, logo seguido por outras obras de assuntos históricos ${ }^{29}$. Apresenta-se como jornalista e historiador ${ }^{30}$ e sua última obra editada é $O$ banqueiro do sertão ${ }^{31}$, na qual retoma uma tese clássica: a das relações entre espanhóis, portugueses e índios no processo de ocupação e exploração do território paulista. Outro autor que produz o que podemos classificar como "obras fronteiriças" é Eduardo Bueno, jornalista, tradutor e escritor prolífico. Suas obras, conforme assinala Yvone Dias Avelino, no artigo acima citado, são de divulgação, porque fundamentadas em obras de historiadores renomados, mas sem introduzir os conhecimentos desenvolvidos nas pesquisas historiográficas posteriores. Suas edições são bem ilustradas e com linguagem jornalística, sem questionamentos, sem problematização, sempre tomando o partido da narrativa fluente ${ }^{32}$.

São Paulo: Companhia das Letras, 2007; DIACON, Todd A.. Rondon: o marechal da floresta. São Paulo: Companhia das Letras, 2006.

25 Mary del Priore é historiadora com diversas obras publicadas, especializada em história de gênero e história do cotidiano. A obra citada é $O$ príncipe maldito. Rio de Janeiro: Ed. Objetiva, 2007.

26 NETO, Jorge dos Santos Caldeira. Voz macia: o samba como padrão de música popular brasileira, 1917-1939. 1989. Dissertação (Mestrado em Sociologia) - Faculdade de Filosofia, Letras e Ciências Humanas, Universidade de São Paulo, 1989 (Orientador: Gabriel Cohn).

27 NETO, Jorge dos Santos Caldeira. Irresponsabilidade, Cidadania e Escravismo na Constituição de 1824. 1998. Tese (Doutorado em Ciência Política) - Faculdade de Filosofia, Letras e Ciências Humanas, Universidade de São Paulo, 1998 (Orientador: Eduardo Kugelmas).

28 CALDEIRA, Jorge. Mauá: o empresário do Império. São Paulo: Companhia das Letras, 1994.

29 Entre outros: CALDEIRA, Jorge. Viagem pela História do Brasil. São Paulo, Companhia das Letras, 1997 (livro e CD-rom); sobre o Brasil, Editora 34, 1999.

30 Cf. a nota final do artigo A esquecida vila da língua tupi, na revista História Viva, no. 3, jan. 2004. Disponível em: <http://www2.uol.com.br/historiaviva/conteudo/ editorial/editorial_3.html>. Acesso em: jun. 2008.

31 CALDEIRA, Jorge. O banqueiro do sertão. São Paulo: Mameluco, 2006. 2 v. (Mulheres no caminho do Prata, 431 p., e Padre Guilherme Pompeu de Almeida, 636 p.).

32 Ver BUENO, Eduardo. Brasil: uma história. A incrível saga de um país. São Paulo: Ática, 2003; Passado a limpo: história da higiene pessoal no Brasil. S.L.: 
Há outras obras, claramente influenciadas pelo desenvolvimento da Ego-história, que são "quase histórias" de família, mas com liberdades literárias - como a que Boris Fausto, cientista político e historiador reconhecido, assume como história de sua família - consideradas como memórias ${ }^{33}$. Também chama a atenção outro tipo de obras que escapam ao campo estrito do conhecimento historiográfico, mas que se identificam como história, como a do arquiteto Luis Augusto Bicalho Kehl ${ }^{54}$, que utiliza fontes documentais e historiografia consagrada para um estudo de origem acadêmica, direcionado para o simbolismo religioso da fundação da cidade de São Paulo.

Não questionamos o fato de, na maior parte das vezes, a obra de "quase história" ter sido editada para suprir as oportunidades comemorativas ou as necessidades de informação e conhecimento de determinado momento. Citamos como exemplo a obra de Roberto Pompeu de Toledo ${ }^{35}$, uma das inúmeras que foram lançadas nas comemorações oficiais dos 450 anos da cidade de São Paulo, e que especificamente atende a inexistência de uma história da cidade acessível aos leitores leigos interessados, mantendo a narrativa fluente, apoiada em bibliografia histórica consagrada (devidamente apresentada no final da edição, para não atrapalhar a leitura), que reforça os mitos de origem paulistas, já devidamente analisados pelos autores especializados nos estudos historiográficos contemporâneos.

$* * *$

Mencionamos até aqui as obras de "quase história", que neste texto recebem o nome de "obras fronteiriças". Para o estabelecimento do gênero "obras fronteiriças", partimos de alguns dados. Inicialmente, o de que um livro de história é produto cultural, inserido no mercado edi-

Gabarito, 2007; Pau-brasil. S.L.: Axis Mundi, 2002; Brasil: terra a vista!, Porto Alegre: L\&Pm Editores, 2000. Além disso, e dentre outras publicações, Bueno organizou Novo Mundo - as cartas que batizaram a América, de Américo Vespúcio, na Ed. Planeta do Brasil, em 2003; e a Coleção “Terra Brasilis”, na Editora Objetiva. Podemos considerar que suas obras atendem as necessidades de informação sobre momentos do passado, que, na fase atual dos estudos históricos, estão dispersas por tantas obras e em formatos tão diferenciados que se torna impossível ao não-especialista reconhecer as relações e formar qualquer compreensão sobre o passado transcorrido e suas análises.

33 FAUSTO, Boris. Negócios e ócios: história da imigração. São Paulo: Companhia das Letras, 1997, que pode ser comparada a de MORIN, Edgar. Um ponto no holograma: a história de Vidal, meu pai. São Paulo: A Girafa, 2006. A ed. francesa é de 1989.

34. KEHL, Luis Augusto Bicalho. Simbolismo e profecia na fundação de São Paulo. São Paulo: Ed. Terceiro Nome, 2005.

35 TOLEDO, Roberto Pompeu de. A capital da solidão. Uma história de São Paulo das origens a 1900. Rio de Janeiro: Objetiva, 2003. 
torial, mas que para ser aceito em estrito senso, pela comunidade dos historiadores, deve atender aos parâmetros acadêmicos, conforme esclarece Michel de Certeau ${ }^{36}$. Em contraposição, existem no mercado editorial nacional diversos produtos culturais que são considerados pelos leitores fora da academia como livros de história, consenso devidamente explorado pelas editoras.

Se o aparecimento de "obras fronteiriças" pode ser associado, em parte e dentre outros fatores, ao esmaecimento das fronteiras disciplinares, promovido pelas transformações epistemológicas e teóricas que ocorreram no último quartel do século $\mathrm{XX}$, devemos levar em conta, na análise do material, alguns aspectos. $\mathrm{O}$ primeiro deles é a relação profunda entre história e literatura, que separadas nas derradeiras décadas do século XIX, no processo de formação de campos especializados, parecem retomar suas relações um século depois, de diversos modos, e um deles parece ser através dos textos biográficos e autobiográficos, que carregam em si mesmos a narrativa literária. Outro aspecto a ser explorado é o da modernização, mesmo que limitada, da sociedade brasileira, que a aproxima do momento pós-moderno que vive a sociedade ocidental. Nele, a fragmentação das identidades individuais faz com que o passado assuma, por um lado, a característica de ser objeto de busca de algo mitificado como homogêneo, como contraponto do momento vivido, ou como curiosidade pela diferença e exotismo, mas deva, por outro, estar inserido no mercado de consumo e do lazer cultural, que Jean Chesneaux discute ${ }^{37}$. Um terceiro e fundamental elemento que deve ser considerado é o poder que a narrativa literária possui de despertar a imaginação - o que explica a permanência das obras de "capa e espada" e dos romances históricos, até nossos dias, assumindo várias outras formas de manifestação, além dos livros, quadrinhos, filmes e séries de TV, reproduzidos em CD-rom e DVDs, nos jogos eletrônicos e digitais.

Assim entendidas e tratadas, não questionamos as múltiplas funções que os livros de "quase história” desempenham. São livros como tantos outros livros, que cumprem sua função cultural e imaginativa.

\section{O campo especializado}

Durante a formação escolar, os professores de história costumavam chamar a atenção para a diferença estrutural entre literatura e história. Aprendemos que eram campos diversos, com exigências di-

36 CERTEAU, Michel de. A operação historiográfica. In: . A escrita da História. Rio de Janeiro: Forense Universitária, 1982.

37 CHESNEAUX, Jean. De la modernité. Paris: La Découverte-Maspero, s.d. 
ferentes: uma era ciência, dotada de procedimentos e convenções, e a outra, arte, criação, invenção.

No curso de graduação em História, o processo de formação do historiador e do professor colocava maior ênfase na especialização do trabalho de pesquisa com fontes e nas formas de interpretação destas, características definidoras do campo. Ainda antes que Michel de Certeau colocasse em termos explícitos as características da escrita historiográfica, a forma de trabalho, a metodologia da história - quer através dos autores metódicos, quer pelas propostas da primeira e da segunda geração do Grupo dos Annales ou pelas leituras das obras do materialismo histórico - eram discutidas, e a prática de pesquisa com fontes documentais assinalava a especificidade do campo.

No último quartel do século XX, a terceira geração do Grupo dos Annales e os estudos culturais interdisciplinares trouxeram novas propostas aos campos historiográficos. $\mathrm{O}$ esmaecimento das fronteiras entre os campos de conhecimento, característica marcante dos estudos culturais, os novos objetos em novas perspectivas, as novas fontes, a preocupação com o estilo e a forma de comunicação, bem como a valorização da subjetividade e da experiência individual, trouxeram a fragmentação ao que parecia ser um campo homogêneo - a história-ciência cedeu espaço a campos historiográficos diversos, cada qual com seus objetos, fontes, metodologia, conceitual analítico, resultados e forma de apresentação.

O impacto de um autor como Hayden White na comunidade dos historiadores pode ser visto como um caso exemplar. Seu livro Metahistória ${ }^{38}$, um brilhante exercício de imaginação teórica, empregou com destreza e convicção as ferramentas da teoria literária para expor as estratégias narrativas dos textos de historiadores e filósofos da história oitocentistas. Posteriormente, no artigo "As Ficções da Representação Factual”, enfatizou o "grau com que o discurso do historiador e do escritor imaginativo se sobrepõem, se assemelham ou se correspondem mutuamente", embora desde o início antecipasse as objeções dos historiadores admitindo que os "eventos históricos" diferem dos "eventos ficcionais" ${ }^{9}$. De todo modo, da leitura de seus textos inferiu-se imediatamente que a historiografia poderia ser reduzida a um gênero literário entre outros, já que se presta à análise pelo emprego dessas categorias. E disso decorreria que suas

38 WHITE, Hayden. Meta-historia: a imaginação histórica do século XIX. São Paulo: EDUSP, 1992. Metahistory: the historical imagination in Nineteenth-Century Europe. Baltimore \& London, 1973.

39 Publicado em WHITE, Hayden. Trópicos do Discurso: ensaios sobre a crítica da cultura. São Paulo: EDUSP, 2001. p. 137. [1. ed. americana, 1978]. "The Fictions of Factual Representation" foi publicado pela primeira vez em The Literature of Fact. N.York: Columbia University Press, 1976. 
pretensões epistêmicas deveriam então ser análogas àquelas das obras literárias. Em nome do que, então, discriminar e excluir mais esse gênero literário histórico - as "obras fronteiriças"?

Admitindo-se provisoriamente esse projeto unificador, talvez fosse possível tratar das "obras fronteiriças" recorrendo aos instrumentos da própria teoria literária, por exemplo, pensando nas características que distinguiriam o romance histórico dos demais romances ${ }^{40}$. Mas ainda restaria a tarefa de distinguir o romance histórico do "romance verdadeiro", como se referiu Paul Veyne à escrita da historia ${ }^{41}$. Igualmente haveria pouco proveito epistêmico em recorrer a distinções qualitativas, por exemplo, tomando a historiografia acadêmica como análoga à grande literatura, diversa da "obra fronteiriça", identificada com a literatura de gosto popular. Isto porque tanto a grande obra literária como os escritos que visam o grande público pertencem ao mesmo gênero - o da ficção. Enquanto que a narrativa histórica, embora permeada por lacunas e faltas, preenchidas por inferências hipotéticas e explicações probabilísticas, reivindica uma categorização não-ficcional.

A obra de ficção parece caracterizar-se pelo papel da imaginação na construção de sua trama. E tendo a imaginação uma função criadora e inventiva, seus produtos, embora por vezes admiráveis, partilham do mesmo modo de ser da fantasia, naquilo em que esta em princípio se opõe à realidade - aquele da não existência factual. Tal é o sentido epistêmico relevante de dizermos que Ivanhoé, D’Artagnan ou Peri e Ceci são personagens de ficção, e que Elizabeth I, Robespierre ou Pedro I são personagens históricos.

Mas este é apenas o desenho de uma polarização ideal. Certamente se pode objetar que, por exemplo, nos assim chamados romances históricos, circunstâncias e cenários construídos em torno de personagens de ficção com freqüência poderiam passar pelos mais estritos crivos de fidedignidade historiográfica. E inversamente, eventos, circunstâncias e personagens históricos com freqüência aparecem capturados nas malhas das mais inverossímeis tramas ficcionais.

Ambas as ocorrências aparecem tipicamente representadas nas "obras fronteiriças", o que as torna intrinsecamente ambíguas, de um ponto de vista epistêmico: o que as define e distingue (também da simples ficção) parece ser a boa certificação histórica de parte de seus elementos constitutivos - personagens, cenários ou episódios. Mas não

40 Por exemplo, o tradicional livro de LUKÁCS, G. Teoria do romance. São Paulo: Duas Cidades/Editora Contraponto, 2000.

41 VEYNE, P. Comment on écrit l'histoire: essai d'épistémologie. Paris: Éditions du Seuil, 1971. 
a sua realidade, no sentido trivial. Trata-se de construções narrativas que respeitam por vezes as convenções discursivas da história, mas tornam-se fronteiriças porque contém passagens de pura invenção, baseadas, contudo, naquilo que sugerem os documentos ${ }^{42}$.

Tal esmaecimento de fronteiras permite pôr em questão o estatuto epistêmico das obras de "quase-história”. Diante da liberdade de tratamento de temas, problemas e recortes, com freqüência a produção acadêmica apresenta-se em formas que se distanciam dos procedimentos convencionais e tradicionais dos estudos históricos: estudos da vida cotidiana nos quais é freqüente o recurso a noções de senso comum pela falta de aparato teórico-analítico; trabalhos com fontes testemunhais que preservam o ponto de vista dos depoentes, sem a intervenção crítica do historiador; inventários descritivos conduzidos sem explicitação de crivos teóricos - o lugar da subjetividade na academia ampliou-se consideravelmente. É freqüente a exposição unilateral de sentimentos e opiniões, e o texto ensaístico muitas vezes toma o lugar do argumentativo.

Quando a própria historiografia acadêmica questiona e torna flexíveis seus valores epistêmicos, quando a idéia de narração parece igualar em uma mesma forma de expressão literatura e história, e o discurso do historiador passa a ser analisado por critérios teóricos emprestados da literatura, como distinguir os dois conjuntos de textos, já que estão quase que umbilicalmente relacionados - fatos, datas, personagens, informações?

Se a designação "quase-história” aplica-se a certa forma menos rigorosa conceitualmente e mais literária de tratar o objeto histórico, podemos considerar que, em nossos dias, ela bem pode caracterizar uma parte representativa da produção acadêmica.

Talvez fosse então necessário dispormos de uma definição rigorosa da obra historiográfica em senso estrito, uma que permitisse distingui-la por critérios inequívocos das obras de estatuto dúbio, que parecem disputar seu campo epistêmico. À primeira vista parece ser essa a solução para o impasse: um critério de corte. Mas a execução não parece ser tão simples.

As obras de "quase história" do século XIX, os romances históricos que tanto contribuíram para a difusão dos mitos românticos das origens nacionais, por exemplo, estavam claramente separadas das obras historiográficas pelo aparato metódico e conceitual que o campo especializado

42 O historiador Simon Schama assim caracteriza sua própria investida numa "obra fronteiriça", o exercício histórico-ficcional "Dead Certainties (unwarranted speculations)", de 1991, no qual utiliza especulação imaginativa acerca de dois eventos, criando relações que não existiram no contexto histórico, o que provocou reações ácidas de historiadores. 
utilizava. Particularmente no final daquele século, a crescente profissionalização do historiador alavancou a questão da demarcação das fronteiras da história científica. Um artigo recente ${ }^{43}$ comenta o caso de J. A. Froude, um historiador bastante popular na Inglaterra vitoriana, que mereceu a censura de Langlois e Seignobos como exemplo do tipo de escrita pouco criteriosa que a nova historiografia crítica deveria superar. A tradução para o inglês do famoso manual ${ }^{44}$ contou com a Introdução do então respeitado Professor Régio de História Moderna de Oxford, F. York Powell, o que consistiu numa chancela de aprovação para estudantes e pesquisadores de língua inglesa quanto aos cânones teóricos e metodológicos da nova disciplina. $\mathrm{O}$ caso vem à tona por ocasião da publicação em inglês do comentário, e provoca uma discussão entre Froude e seus críticos, bastante iluminadora quanto aos temas em jogo na delimitação de fronteiras entre os dois tipos de escrita da história - o literário e o acadêmico. Parece-nos que algo semelhante, porém às avessas, pode estar ocorrendo em nossos dias.

A preocupação com a demarcação de fronteiras das áreas de investigação propriamente científicas, para distingui-las da falsa ciência e das atividades de divulgação, é recorrente na reflexão acerca do conhecimento e seus modos de produção. A questão da demarcação não só interessa aos estudos teóricos de epistemologia ${ }^{45}$, como tem aplicações práticas. A autoridade e confiabilidade do adjetivo "científico" com freqüência são invocadas para referendar a qualidade de vários produtos e serviços. Em muitos casos, uma boa aplicação de critérios de demarcação pode auxiliar a tomar decisões e evitar erros de avaliação, por vezes com conseqüências graves - basta considerar situações que exijam conhecimento médico, ou legal, ou ambiental, por exemplo.

43 HESKETH, Ian. Diagnosing Froude's disease: boundary work and the discipline of history in late-Victorian Britain. History and Theory, 47, p. 373-395, out. 2008. A expressão "boundary work" é empregada pelo autor para designar o trabalho disciplinar de demarcação de fronteiras, não a obra fronteiriça enquanto tal, que tematizamos aqui.

44 LANGLOIS, C.V.; SEIGNOBOS C. Introduction aux études historiques. Paris: Hachette, s.d.; Introduction to the study of history. Trad. G.G. Berry. New York: Henry Holt \& Company, 1898.

45 Para os epistemólogos - teóricos contemporâneos do conhecimento em qualquer de suas formas e manifestações, científicas, culturais ou de senso comum - a discussão acerca das fronteiras do conhecimento científico de fato se traduz no problema da justificação das opiniões e crenças que consideramos verdadeiras. Ver: CHILSHOLM, R. M. Theory of knowledge. 3. ed. Englewood Cliffs, NJ: Prentice-Hall, 1989; AUDI, R. Epistemology: a contemporary introduction to the theory of knowledge. London: Routledge, 1998; DANCY, J. Epistemologia contemporânea. Lisboa: Edições 70, 2002; LEHRER, K.. Theory of knowledge. Boulder: Westview Press, 1990; SOSA, E. Knowledge in perspective: selected essays in epistemology. Cambridge: Cambridge University Press, 1995. 
Certamente aquilo que denominamos ciência é o resultado de um longo processo histórico, e muitas circunstâncias contingentes podem interferir em nossa concepção do que pode ou não ser considerado conhecimento científico. Contudo, há um razoável consenso quanto a todas as especialidades acadêmicas serem produtoras de conhecimento confiável - incluindo as humanidades. E nesse sentido, as falsas representações dos pseudo-historiadores seriam de natureza muito semelhante àquelas dos alquimistas ou criacionistas.

A demarcação das fronteiras como questão parece surgir de tempos em tempos, toda vez que há uma crise de paradigmas, tanto na decifração da natureza como nos saberes acerca do homem e da história ${ }^{46}$. Tomando como exemplo a teoria da ciência no século $\mathrm{XX}$, podemos recordar a ampla discussão provocada pelos escritos de Karl Popper sobre a natureza do conhecimento científico - sobretudo na década de 70, entre nós. Dentre outros temas, Popper insistiu na função de sua proposta de falseacionismo metolodógico como critério de demarcação: teorias que tudo explicam, e não propõem instâncias de sua própria possível falseação, violam a condição mais fundamental da cientificidade - a de submeter-se (e sobreviver) a testes potencialmente falseadores. Por tal critério poderíamos demarcar a cientificidade da astronomia, por exemplo, mas não da astrologia - a qual nunca é posta de fato à prova, porque consiste numa fonte inesgotável de justificações para toda e qualquer anomalia em suas previsões ${ }^{47}$.

Popper propunha-se a corrigir as posições verificacionistas propostas pelos positivistas lógicos do Círculo de Viena nos anos 30. Por sua vez, seu falseacionismo foi objeto de inúmeras contestações. Talvez a oposição mais famosa seja a de Thomas Kuhn ${ }^{48}$, que defende que a atividade científica regular - a "ciência normal" - ocupa-se menos de falsificação do que da solução de quebra-cabeças. A característica de propô-los e tentar

46 Alguns fazem remontar a questão a Aristóteles, nos Segundos analíticos. Ver LAUDAN, L. The demise of the demarcation problem. In: R.S. Cohan \& L. Laudan. Physics, philosophy and psychoanalysis. Dordrecht: Reidel, 1983.

47 Por exemplo, ver POPPER, K.. A lógica da pesquisa científica. São Paulo: Edusp/ Cultrix, 1975. [1. ed. inglesa 1959]. Conhecimento objetivo. Belo Horizonte: Itatiaia, 1975. Conjecturas e refutações. Brasília: Ed. UNB, 1972. A bibliografia popperiana sobre o tema é ampla e variada, além dos diálogos e polêmicas que suas posições suscitaram.

48 KUHN, T.. A estrutura das revoluções científicas. São Paulo: Perspectiva, 1978. De inspiração kuhniana o artigo de GIERYN, Thomas F.. Bondary-work and the Demarcation of Science from Non-Science: Strains and Interests in Professional Ideologies of Scientists. American Sociological Review, v. 48, n. 6, p. 781-795, dec. 1983. Aqui também a expressão "boundary work" é empregada pelo autor para designar a discussão disciplinar de demarção de fronteiras, não o estatuto da obra situada na fronteira. 
resolvê-los é típica da atividade científica. Um critério que Popper considerou de tipo sociológico e externo à racionalidade científica.

A discussão sobre o tema tem seqüência até nossos dias. A tendência entre os autores contemporâneos é não considerarem apenas um critério de demarcação, mas listas de vários critérios, a serem empregados conjuntamente para identificar as práticas pseudo-científicas ${ }^{49}$. Tais listas em geral combinam tanto aspectos intrínsecos às operações científicas quanto situações e atitudes de cunho mais sociológico e cultural. Porém, embora tais indicações consistam em parâmetros judiciosos para balizar os campos de conhecimento, contudo não fornecem um critério inequívoco para o recorte das fronteiras disciplinares.

A questão das “obras fronteiriças" em história coloca, pois, o problema da demarcação. Ora, de modo geral, o que se depreende da discussão epistemológica sobre as fronteiras do conhecimento cientifico é que há muito mais possibilidade de consenso quanto à aplicação de critérios de demarcação a casos particulares e específicos, conforme a necessidade, do que quanto às definições dos limites que orientam tais decisões. Assim, se as grandes linhas epistemológicas da questão permanecem abertas à discussão, analogamente, será provavelmente mais proveitoso discutir a aplicação de critérios de corte examinando as obras fronteiriças caso a caso, sempre que a questão surgir.

$$
* * *
$$

A tarefa de demarcação das fronteiras e de sua vigilância é reivindicada pela historiografia acadêmica. Trata-se certamente de uma herança disciplinar cujos caminhos também podem ser retraçados por uma investigação histórica. Mas seu exercício é parte integrante de nossa compreensão dos procedimentos que caracterizam a obtenção e justificação do conhecimento confiável - na História como nas demais ciências. E como toda atividade policial, é exercida em meio a pressões e polêmicas. A demanda externa de editores para atender um público leitor mais amplo não pode ser ignorada. Mas contam também as tensões internas da comunidade dos historiadores. Lawrence Stone, no conhecido artigo de 1979, já diagnosticava que os "novos historiadores" retornavam à forma narrativa possivelmente

49 Por exemplo, MAHNER, M. Demarcating science from non-science, p 515-575. In: KUIPERS, T. (Ed.) Handbook of the philosophy of science: general philosophy of science - focal issues. Amsterdam: Elsevier, 2007; GLYMOUR, C;.STALKER, D. Winning through pseudoscience. In: GRIM, P. (Ed.) Philosophy of science and the occult. 2. ed, Albany: State Univ. of NY Press, 1990. p. 92-103; RUSE, M. (Ed.) But is it science? The philosophical question in the creation/evolution controversy. S.L.: Prometheus Books, 1996. 
para atingir um público culto porém mais amplo do que o restrito círculo de especialistas, único capaz de discutir as monografias dos historiadores estruturais e quantitativos, caras e com edições reduzidas, compradas quase que exclusivamente por bibliotecas ${ }^{50}$.

Que valor pode ter então uma "obra fronteiriça"? Propomos que ela tenha um valor heurístico. Recriar pela imaginação tem alcance não só de fruição artística e literária, ou até mesmo de ensinamento moral, mas pode perfeitamente auxiliar a compreensão histórica. As situações por elas retratadas, pela vivacidade com que apelam à imaginação criadora, podem desempenhar papel coadjuvante naquilo que Thomas Kuhn denominou "psicologia da pesquisa" ${ }^{51}$ - 0 amálgama um tanto indiferenciado de idéias recebidas, visões de mundo e motivações pessoais que constituem a vivência subjetiva da pesquisa, por oposição à exposição metódica do tema, argumentos e procedimentos, pública e submetida objetivamente ao exame crítico da comunidade científica. Uma "obra fronteiriça” bem construída pode inspirar o aluno, o iniciante, mesmo o pesquisador experiente, na pintura imaginária do cenário, na identificação prévia dos problemas em jogo, na construção de hipóteses, na visão da solução para algum impasse interpretativo. Mas, se de tal imaginário brotar um trabalho com pretensões historiográficas, certamente não os dispensará da construção justificada da pesquisa segundo os critérios demarcados pela comunidade dos historiadores acadêmicos.

Eis então a nossa fronteira entre os dois gêneros. Quem avalia o valor historiográfico da literatura de ficção histórica? Isso só pode ser feito a partir dos princípios e práticas em uso no território demarcado pela fronteira da cientificidade - aquele dos historiadores. Certamente haverá graus de acuracidade nas recriações fronteiriças; caberá à historiografia acadêmica avaliá-los criticamente, caso a caso. Mas as liberdades narrativas inerentes à escrita literária podem ter valor propedêutico - o de pavimentar o caminho da compreensão histórica.

Recebido em 26 de janeiro de 2009

Aprovado em 18 de fevereiro de 2009

50 STONE, Lawrence. The revival of narrative. Past and Present, 1979. $\mathrm{O}$ ressurgimento da narrativa: reflexões sobre uma nova velha história. Revista de História. Campinas, n.2/3, 1991, p. 27.

51 KUHN, Thomas S.. Logic of discovery or psychology of research?. In: SCHILLP, P. A. (Ed.) The philosophy of Karl Popper. La Salle: Open Court, 1974. 